\title{
Enhance Some Insulation Properties of Epoxy by Using Waste Materials
}

\author{
Besma M. Fahad \\ Afaf Abdulhussein Naser \\ Material Eng. Dep., Al-Mustansiriyah Uni., Baghdad, IRAQ \\ afaf_alshmari@yahoo.com \\ Received: 16-Oct.-2017 \\ Revised: 03-Dec.-2017 Accepted: 18-Jan.-2018

\begin{abstract}
http://doi.org/10.29194/NJES21020259
\end{abstract}
\begin{abstract}
Particles filled polymer composites started to be essential because of their wide applications in addition to reducing the cost of polymer, which is a main problem. The aim of this work is studying the insulation of particulate composites resulting from the addition of filler (glass or porcelain) waste powder to reinforced epoxy matrix. Samples with and without filler were exposed to some tests to decide the influence of the filler contents on the characteristics of epoxy. Epoxy is synthesized with filler particles having (90 micron) particle sizes as reinforcement. Composites of epoxy with varying percentage ( 0 to 40 weights \%) of filler were prepared by using hand lay-up method. The nondestructive tests consist of thermal conductivity; ultrasonic test and water absorption test have been investigated. The composite showed an improvement in physical properties with the addition of filler according to their percentages. The result show the addition of the filler in all proportions to the epoxy increased the density of the composite, leading to the ultrasonic pulses velocity ranges between $2100 \mathrm{~m} / \mathrm{s}$ and $2800 \mathrm{~m} / \mathrm{s}$. Increase glass and porcelain percentage cause increase in density which increases the acoustic impedance. While the thermal conductivity decrease with glass powder percentages in the composite increase, unlike the increase in porcelain percentage which causes an increase in thermal conductivity. The $40 \%$ percentage of glass in the epoxy had higher effect on reduce the thermal conductivity. As well as from the results the epoxy reinforced by porcelain powder would have lower water absorption than epoxy reinforced by glass powder.
\end{abstract}

Keywords: WG (waste glass), porcelain, epoxy risen, physical properties.

\section{Introduction}

Epoxy is commonly used as a substance in many applications. Thermosetting resin (epoxy) possesses special characteristics like compact or none volatiles formation during curing. Various curing temperatures, as well as, a flexible degree of cross-linking, which can easily be controlled, On the other hand, epoxy resin is also known for its being inherently brittle and exposed to fracture with low toughness, in addition to its poor durability to crack propagation with low impact strength. These are seen as among its main disadvantages [1].

In order to avoid such disadvantages and enhance its characteristics, epoxy is subjected to a number of reinforcements, such adding fillers which may include, but not limited to, glass-fiber [2], silica powder, and/or aramid fiber [3] the type of added filler may largely depend upon the specific type of application for which epoxy is used Composites material can also provide various filler options to epoxy. Unfortunately, the number of studies and experiences in relevance to the types of fillers used For such purposes, the effect of each type of reinforcement filler, and its suitability for each application, is still too limited to provide a competent database that can supply engineers and experts with the features of each type before the process of selection for potential filler [4]. Ceramic filler, more specifically porcelain or glass was combined with epoxy resin in the current work, as a reinforcement material, improving the thermal as well as the physical characteristics of the epoxy, Moreover, the homogeneity of dispersal of the porcelain and glass particles can guarantee a further enhancement to the finally created composites. Porcelain and waste glass reinforced epoxy is discussed in this study and physical tests like thermal conductivity, ultrasonic pulse velocity test and water absorption were conducted as per ASTM.

\section{Experimental Procedure \\ 2.1. Materials System \\ 2.1.1. Epoxy}

The matrix material used in the present study is epoxy types (EUXIT 50) non-pigmented consists of two units for the preparation of liquid epoxy resin and formulated amine hardeners.

It is supplied by (SWISSCHEM) Company / Swiss. Specific gravity is 1.05 at $20 \mathrm{C}^{\circ}$ and viscosity of 300 cps poison, where the required ratio is $3: 1$, resin to hardener.

\subsubsection{Waste Glass (WG)}

The source of waste glass used in this work was the waste of windows Turkey-made glass collected from local windows glass venders. The thickness of the Glass was $4 \mathrm{~mm}$. After collecting it, the WG was cleaned, crushed and sieved in order to obtained particle size of 90 micron. The physical properties of crushed WG are shown in Table (1). 


\subsubsection{Porcelain powder}

Porcelain powder used in this research was collected from the waste material of construction remaining on working sites after they were brought in the lab and crushed using Jaw crusher then powdered by The HERZOG pulverizing mill HSM and sieved by auto sieve shaker to reach particles of 90 micro sizes. Physical properties of the porcelain are shown in the table (1).

Table (1): Chemical and Physical properties of Windows Waste Glass, Porcelain powder and epoxy.

\begin{tabular}{|c|c|c|}
\hline Material & Specific Gravity & Density $\left(\mathrm{Kg} / \mathrm{m}^{3}\right)$ \\
\hline WG & 2.6 & 2600 \\
\hline Porcelain & 2.4 & 2400 \\
\hline Epoxy & 1.05 & 1050 \\
\hline
\end{tabular}

\section{Experimental Work}

Composites of epoxy were synthesized with filler (glass and porcelain powder) having (90 micron) particle sizes as reinforcement. Different mixtures of polymer composite were prepared to study their effect on a polymer. The first set includes WG with percentages (10, 20, 30 , 40 )\% while the other set includes porcelain powder with percentages $(10,20,30,40) \%$ As the mixture is achieved in a ratio of $3: 1$ resin to hardener which form epoxy (Euxit 50), the filler added to the epoxy to form particulate composites. The particulate composites obtained through the process of mixing the two components, adding the filler for 10 minutes at $\left(27 \mathrm{C}^{0}\right)$ towards achieving a homogeneous mix. On completing the mixing process, the outcome composite was poured into molds that have already been coated with mineral oil in order to avoid the adhesion of the composite to the mold. The accomplishment of the casting process needed the work to be down in three layers. Each of these layers needed compacting for 1-1.5 minutes, using a vibrating device, in order to get rid of any air bubbles within the composite. After the curing is complete in $24 \pm 2$ hours, the specimens were de-molded. and then curing process took seven days to finish at room temperature, due to the epoxy construction.

\subsection{Tests}

A nondestructive test on polymer-filler composites were carried out. The nondestructive tests consist of thermal conductivity, ultrasonic pulse velocity and water absorption tests.

\subsubsection{Density Test}

The density of the particulate composite were determined according the stander procedure (ASTM C138) [5] in $\left(\mathrm{kg} / \mathrm{m}^{3}\right)$, was found by weighing the specimens and dividing the values (mass in kilograms) by the volume of the specimen. Table (3) shows the result.

\subsubsection{Ultrasonic Pulse Velocity Test (UPV)}

Sound waves are vibrations of particles of gases, solids or liquids. The audible sound range of frequencies is usually taken from $20 \mathrm{~Hz}$ to 20 $\mathrm{KHz}$. Sound waves with frequencies higher than $20 \mathrm{KHz}$ are known as ultrasonic waves. [6]

This test was implemented according to British standard BS1881: part 203 [7], via a portable ultrasonic indicating tester (PUNDIT Lab PROCEQ Co.) Switzerland, shown in plate (1). the process required the use of two transducers that were fitted the device, the first acted as transmitter of the ultrasonic pulses, while the second was a receiver of them. Using a coupling agent, both of the transducers were positioned by the specimen's surface to ensure good pulse transmittance. Here, a $54 \mathrm{KHz}$ resonant frequencies pulse of longitudinal vibration was produced, using an electroacoustical transducer which was later converted into an electrical signal via a receiver transducer. An electronic timing circuit carried out the timing of the pulse transit. Velocity (The speed with which energy is transported between two points in a medium by the motion of waves is known as the velocity of the waves. It is usually denoted by the letter V. in this test the samples used have dimension (50 mm cube), see Plate (1).

The calculation of the velocity $(\mathrm{V})$ in $(\mathrm{m} / \mathrm{sec}$.) was: $\mathrm{V}=\mathrm{L} / \mathrm{t}$ (1) [6].

$\mathrm{L}=$ distance between centers of transducer faces, (m) $\mathrm{t}=$ transit time (micro sec.), Table (2) show the result.

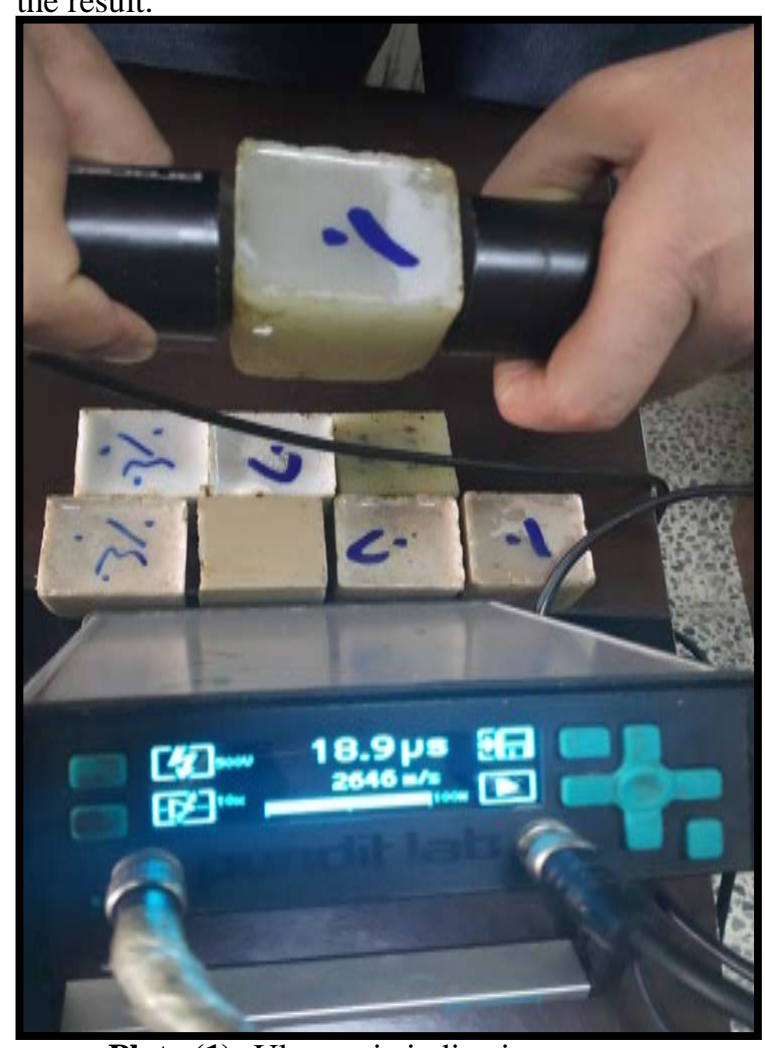

Plate (1): Ultrasonic indicating tester. 
Table (2): Result Ultrasonic Pulse Velocity Test.

\begin{tabular}{|c|c|c|}
\hline Material & $\begin{array}{c}\text { Transit } \\
\text { Time } \\
\text { (micro sec.) }\end{array}$ & $\begin{array}{c}\text { Wave Velocity } \\
\text { (m/s) }\end{array}$ \\
\hline Glass 10\% & 19.4 & 2578 \\
\hline Glass 20\% & 18.9 & 2646 \\
\hline Glass 30\% & 18.4 & 2718 \\
\hline Glass 40\% & 17.8 & 2810 \\
\hline Porcelain 10\% & 20.9 & 2393 \\
\hline Porcelain 20\% & 19.9 & 2513 \\
\hline Porcelain 30\% & 19.2 & 2605 \\
\hline Porcelain 40\% & 18.2 & 2748 \\
\hline
\end{tabular}

\subsubsection{Acoustic Impedance $(Z)$}

Sound travels through materials under the influence of sound pressure. Because molecules or atoms of a solid are bound elastically to one another, the excess pressure results in a wave propagating through the solid.

The acoustic impedance $(\mathrm{Z})$ of a material is defined as the product the density $(\rho)$ of the material multiplied by the velocity (V) of sound, shown in the equation (2) [6]. Table (3) shows the result.

The value of the acoustic impedance depends on its physical properties.

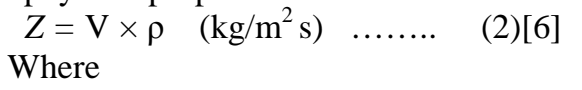

$\rho$ is the density $\left(\mathrm{kg} / \mathrm{m}^{3}\right)$

$\mathrm{V}$ is the ultrasonic velocity $(\mathrm{m} / \mathrm{s})$

Density $\rho=\mathrm{m} / \mathrm{Vol} . \quad\left(\mathrm{kg} / \mathrm{m}^{3}\right)$

$\mathrm{m}$ mass of the sample $(\mathrm{kg})$

Vol. volume displaced or increased $\left(\mathrm{m}^{3}\right)$

Acoustic impedance is important in determination of acoustic transmission and reflection at the boundary of two materials, and assessing absorption of sound in a medium.

Table (3): Result of Acoustic Impedance.

\begin{tabular}{|c|c|c|c|}
\hline Material & $\begin{array}{c}\text { Wave } \\
\text { Velocity } \\
\mathbf{m} / \mathbf{s}\end{array}$ & $\begin{array}{c}\text { Density, } \\
\mathbf{\rho} \\
\mathbf{( k g / \mathbf { m } ^ { 3 } )}\end{array}$ & $\begin{array}{c}\text { Acoustic } \\
\text { Impedance } \\
\mathbf{1 0}^{\mathbf{6}} \mathbf{~ k g} / \mathbf{m}^{2} \mathbf{~ s}\end{array}$ \\
\hline Glass 10 \% & 2578 & 1120 & 2.88 \\
\hline Glass 20 \% & 2646 & 1244 & 3.29 \\
\hline Glass 30 \% & 2718 & 1290 & 3.50 \\
\hline Glass 40 \% & 2810 & 1318 & 3.70 \\
\hline $\begin{array}{c}\text { Porcelain } \\
10 \%\end{array}$ & 2393 & 1095 & 2.62 \\
\hline $\begin{array}{c}\text { Porcelain } \\
20 \%\end{array}$ & 2513 & 1164 & 2.92 \\
\hline $\begin{array}{c}\text { Porcelain } \\
30 \%\end{array}$ & 2605 & 1180 & 3.17 \\
\hline $\begin{array}{c}\text { Porcelain } \\
40 \%\end{array}$ & 2748 & 1227 & 3.37 \\
\hline
\end{tabular}

\subsubsection{Thermal Conductivity Test}

The thermal properties of specimens were (20 mm thickness $\times 50 \mathrm{~mm}$ width $\times 100 \mathrm{~mm}$ length) which measured by using (power supply; QTM-
500 meter; Kyoto Electronics Manufacturing, Japan) as shown in plate (2). It is ranged from 0.023 to $12 \mathrm{~W} / \mathrm{mk}$ according to the ASTM C 1113 [8] hot - wire approach due to the fact that the latter is a faster and more accurate for obtaining the measurements of thermal conductivity. The process includes placing of sensor probe (PD-11) on top of the rectangular. Both parts, sensor probe and the rectangular specimens must be of different sizes, where the latter must be larger in size in order to guarantee accurate measurements, since no heat lost is dedicated. A constantan made of copper-nickel alloy wire heater and a chromel alumel thermocouple are the two main components forming the sensor probe. The thermocouple role is to monitor the heat flow, when the heat supply is provided via the heating wire. On finishing the measurement, the screen will display results in an exact hour (60min.)

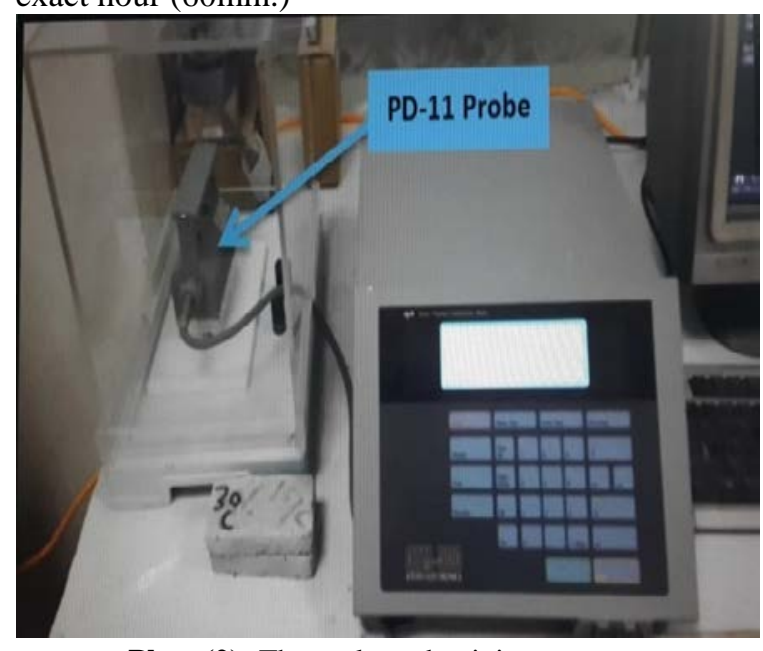

Plate (2): Thermal conductivity meter.

\subsubsection{Absorption Test}

The purpose of water absorptivity test is to determine the amount of water that the particulate composite can absorb during raining season or down fall in relation to its weight.

The absorption test of water was determined in accordance with the ASTM D 570 [9]. The disk used in the test specimen is of $50.8 \mathrm{~mm}$ (2 in.) in diameter and $3.2 \mathrm{~mm}$ (1/8 in.) thickness in measurements, (see plate (3), the obtained specimens composite were placed in a container filled with distilled water of $23^{\circ} \mathrm{C}$ in temperature, these are to be left to rest on the edge, after being entirely immersed. This described process is to take a full $24 \mathrm{~h}$, all the specimens are to be lifted from the container all together. All surface water should be wiped off with a dry cloth, and then they are to be weighed to the nearest $0.001 \mathrm{~g}$ directly.

The percentage water absorptivity was calculated and recorded against each mass. The percentage increase in weight during immersion was calculated using the following equation.

$$
m=\frac{w-w o}{w o} \times 100 \%
$$


Where $\mathrm{m}, \mathrm{w}, \mathrm{w}_{0}$ are the moisture absorption content, weight of dried and wet composite material respectively [9].

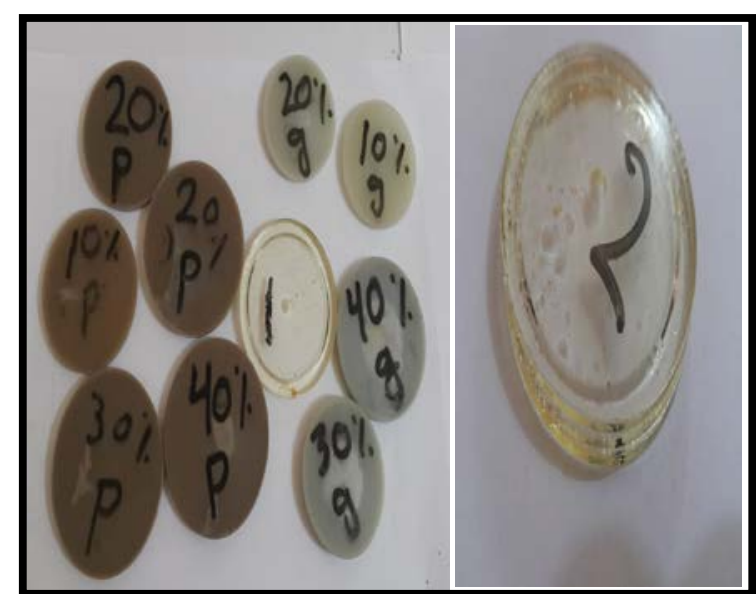

Plate (3): The test specimen for water absorption.

\section{Results and Discussion}

\subsection{Ultrasonic Pulse Velocity Test}

In order to evaluate the uniformity of particulate composites as well as calculate the transmitting time of waves, this type of test is implemented. Useful data concerning interior structure in addition to cracks of particulate composite specimens is obtained using this test, see table (2). Figure 4, 5, and 6 state the final results the ultrasonic test.

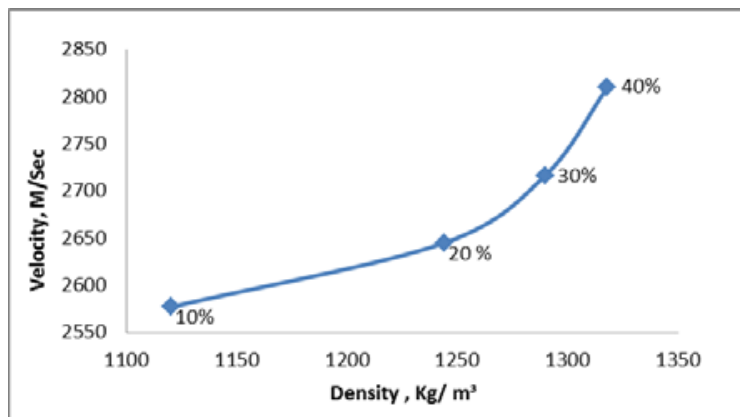

Figure (4): Ultrasonic velocity of glass waste epoxy composites

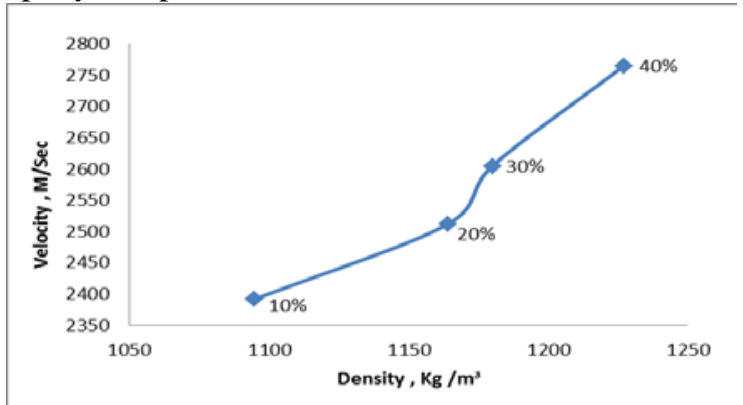

Figure (5): Ultrasonic velocity of porcelain -epoxy composite

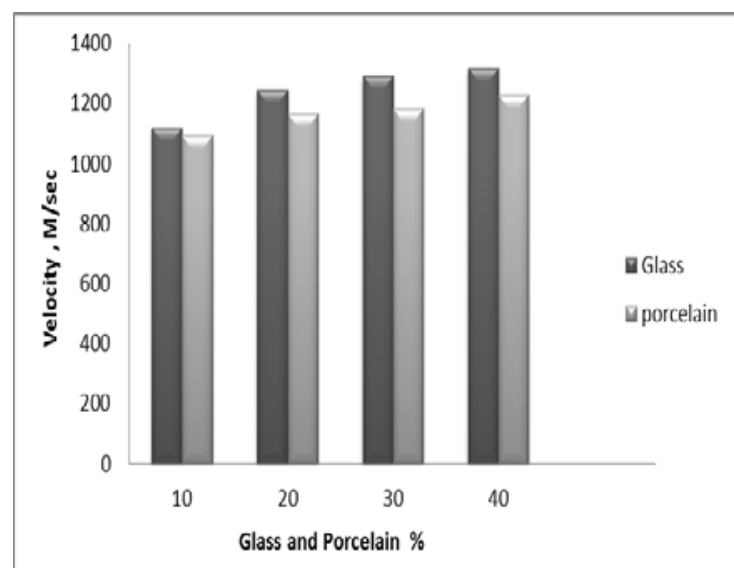

Figure (6): Comparison between the Ultrasonic velocities of composites in different proportions.

The following observations are obtained through the test results:

1. The addition of the filler in all proportions to the epoxy increased the density of the composite, indicating the homogeneity of the composite, leading to the ultrasonic pulses velocity ranges between $2350 \mathrm{~m} / \mathrm{s}$ and $2810 \mathrm{~m} / \mathrm{s}$, see table (3).

2. For glass composite the higher velocity is $2810 \mathrm{~m} / \mathrm{sec}$. for $40 \%$ percentage at room temperature.

3. High filler content Composite revealed an increase in velocity as compared with that of low content. Such behavior can be explained by the surface texture and high density of composite.

4. The wave velocity values of epoxy reinforced by waste glass are higher than that of epoxy reinforced by porcelain.

5. The composite with glass particles at ratio (40\%) gives the high results and this is due to good interface between epoxy and filler particles and minimizes the voids in the composites.

\subsection{Acoustic Impedance ( $Z$ )}

The acoustic impedance of the composite has different value as show in the figures $(7,8$, and 9$)$.

Increase in glass or porcelain percentage cause increase in density which increases the acoustic impedance.

The acoustic impedance values of epoxy with glass or porcelain powder can be explained by density and velocity variation. The variation of molecular structure in polymer, such as length or/and orientation of the chains of polymer are likely resulted from the corresponding changes of sound velocity and/or attenuation. Changes in grain size or orientation in polymer would leads to some changes in the amplitude, direction, and frequency of ultrasound. Different axes of a solid material are to be used to determine and calculate 
anisotropy with variation in sound velocity, scattering, and attenuation [10].

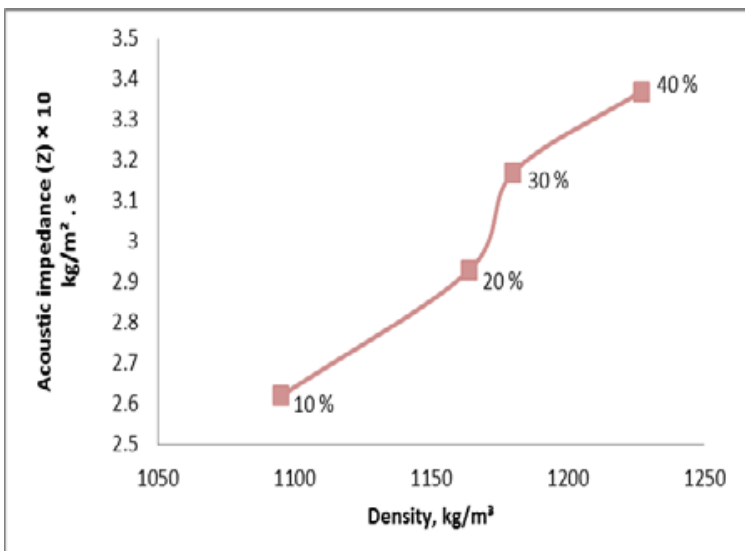

Figure (7): Effect of porcelain composite and density on the acoustic impedance.

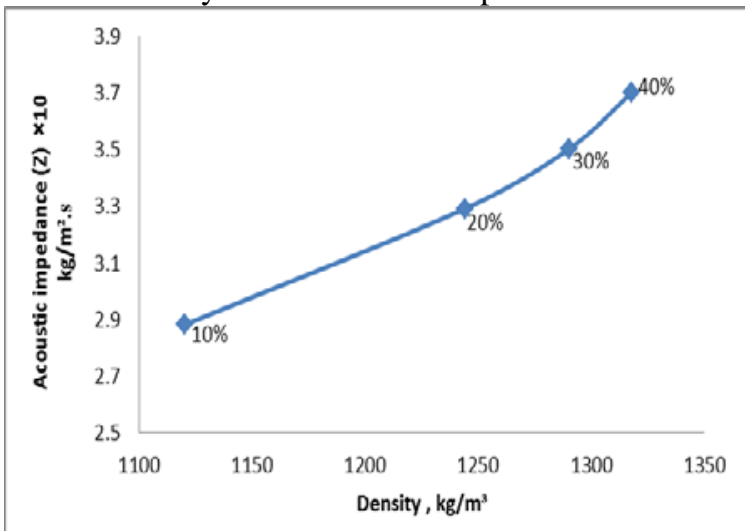

Figure (8): Effect of glass composite and density on the acoustic impedance.

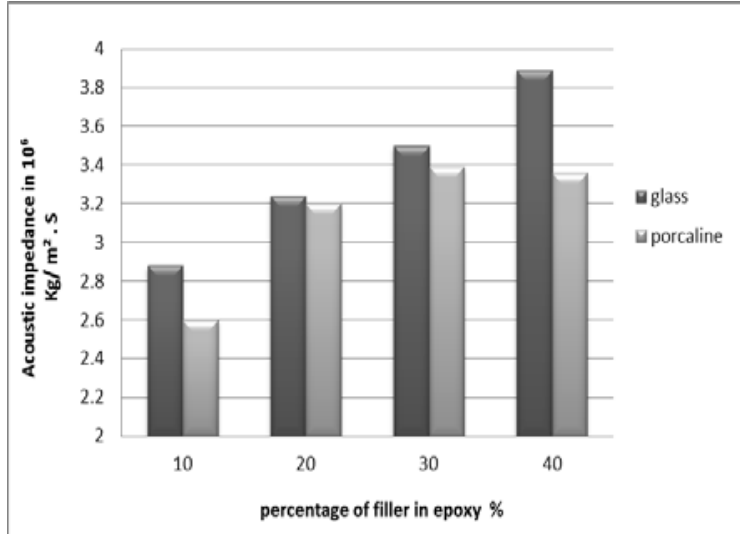

Figure (9): Comparison between acoustic impedance with difference percentages of glass and porcelain composite.

\subsection{Thermal conductivity}

Glass and porcelain powder influences the thermal conductivity of composite as shown in figures $(10,11$, and12). The thermal conductivity decrease with glass powder percentages in the composite increase, unlike the increase in porcelain percentage which causes an increase in thermal conductivity, this behavior is because the glass has a low thermal conductivity coefficient than epoxy, which makes it better in thermal insulation.

The $40 \%$ percentage of glass in the epoxy had higher effect on the thermal conductivity than the porcelain powder.

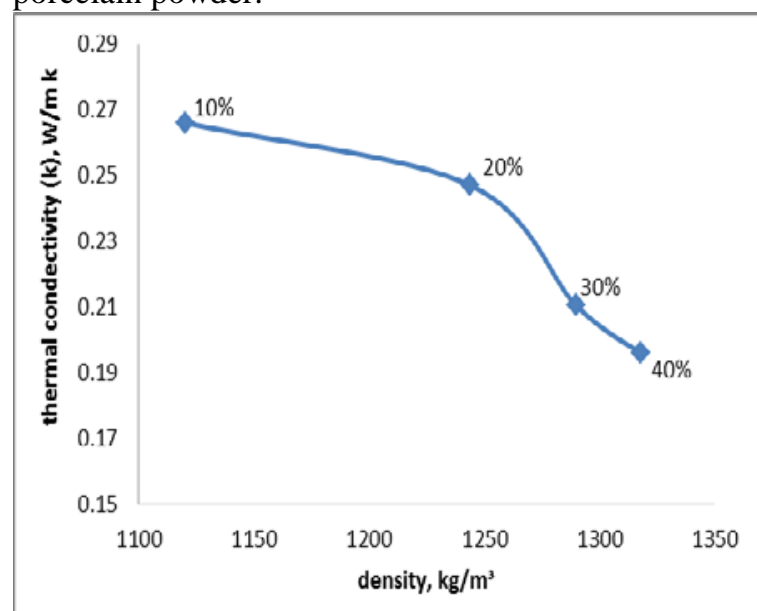

Figure (10): Effect of glass composite on thermal conductivity

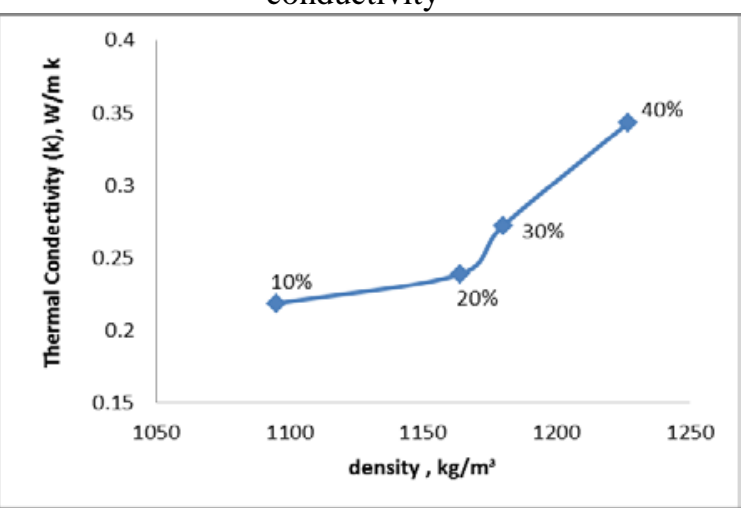

Figure (11): Effect of porcelain composite on thermal conductivity.

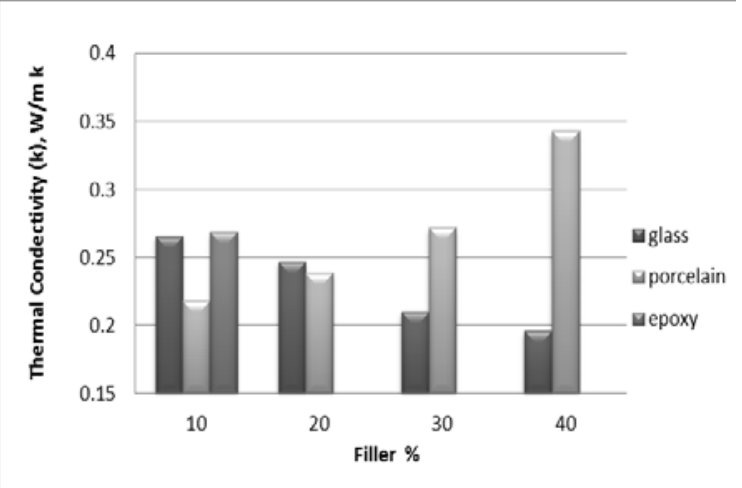

Figure (12): Comparison of conductivity with filler percentage in the epoxy and epoxy separately.

As Fig.(12) shows comparison of thermal conductivity with filler (glass or porcelain) percentage, despite this increase of thermal conductivity when addition porcelain powder to epoxy, the percentage $(10,20$, and 30$) \%$ is still less than the epoxy separately. Therefore all 
percentages are good and improve the thermal insulation except when addition $40 \%$ porcelain composite

\subsection{Water Absorption}

Water absorption of composite specimens was measured. The results show that water absorption decreases with the increase of porcelain percentage beside the epoxy reinforced by porcelain powder would have lower water absorption than epoxy reinforced by glass powder, because composite with porcelain content shows lower voids compared with glass content, and the reduction in water absorption resulted from the porcelain particles does not absorb water and only the hydrated part of the matrix retain water [11]. As shown in figure (13, 14, and 15). The results obtained from the Water Absorptivity Rate Test are indicated in table (4).

Table (4): Rate of Water Absorptivity.

\begin{tabular}{|c|c|c|c|}
\hline Specimen & $\begin{array}{c}\text { Dry } \\
\text { pieces } \\
\text { Weight } \\
\text { (gm) }\end{array}$ & $\begin{array}{c}\text { Weight of } \\
\text { the } \\
\text { Water } \\
\text { content } \\
\text { (gm) }\end{array}$ & $\begin{array}{c}\text { Average \% } \\
\text { of Water } \\
\text { Absorption }\end{array}$ \\
\hline Epoxy & 16.47 & 16.50 & 0.1821 \\
\hline $\begin{array}{c}\text { Porcelain } \\
10 \%\end{array}$ & 10.66 & 10.67 & 0.0938 \\
\hline $\begin{array}{c}\text { Porcelain } \\
20 \%\end{array}$ & 16.35 & 16.36 & 0.0611 \\
\hline $\begin{array}{c}\text { Porcelain } \\
30 \%\end{array}$ & 18.69 & 18.70 & 0.0535 \\
\hline $\begin{array}{c}\text { Porcelain } \\
40 \%\end{array}$ & 23.15 & 23.16 & 0.0431 \\
\hline Glass 10\% & 11.36 & 11.38 & 0.1760 \\
\hline Glass 20\% & 10.90 & 10.919 & 0.1724 \\
\hline Glass 30\% & 17.48 & 17.51 & 0.1716 \\
\hline Glass 40\% & 21.64 & 21.67 & 0.1386 \\
\hline
\end{tabular}

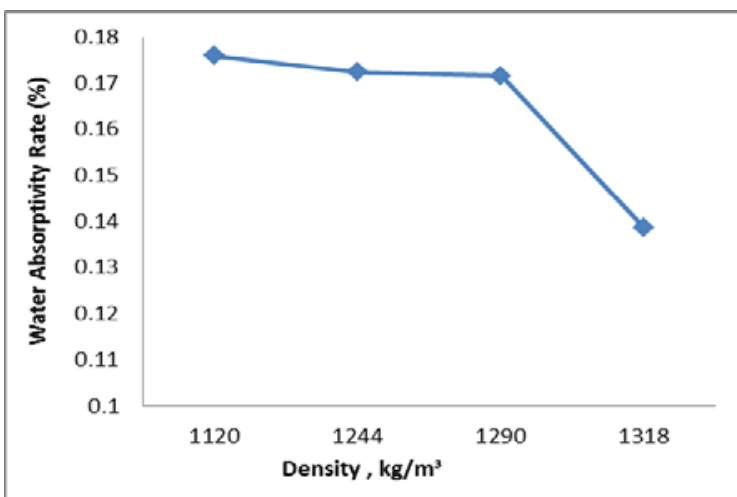

Figure (13): Effect of glass density on the water absorption.

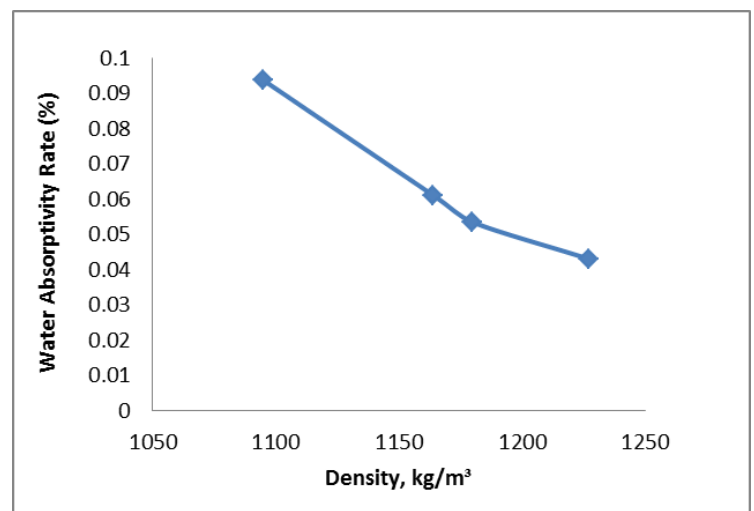

Figure (14): Effect porcelain density on the water absorption

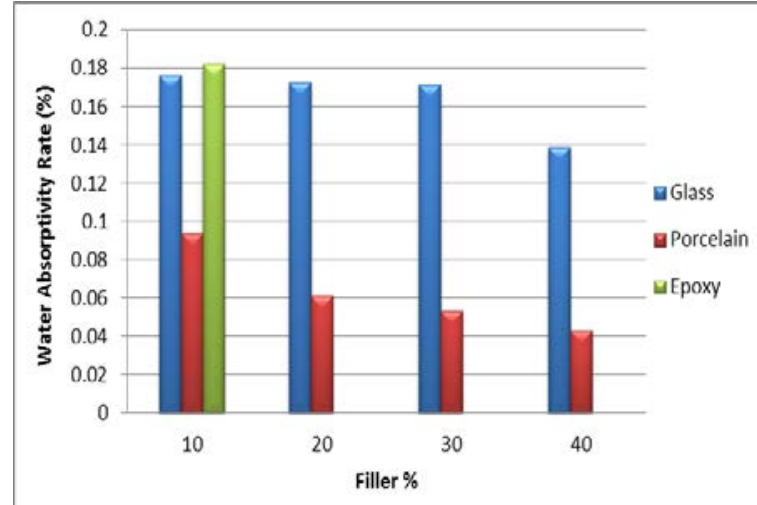

Figure (15): Comparison of water absorptivity rate with filler percentage in the epoxy and epoxy separately.

Figure (15) shows comparison of water absorption and filler (glass and porcelain) percentage; despite this the composite reinforced by porcelain powder at $40 \%$ percentage had the lowest absorption. However all the percentage of the glass and porcelain are still less than the epoxy separately. Therefore, all percentages are successful in decreasing the water absorption.

\section{Conclusions}

It is found out that by adding filler to the epoxy the density of particulate composites increased, and all insulation properties improves

As far as the features of acoustic impedances, the increase of filler increased the acoustic impedances compared to glass composite. The latter is more competent than the former. The $40 \%$ percentage of glass in the epoxy had higher effect on the acoustic impedance $\left(3.70 \times 10^{6} \mathrm{~kg} / \mathrm{m}^{2} \mathrm{~s}\right)$

On the other hand, in the thermal conductivity test, glass proved to reduce thermal conductivity while it was increased with porcelain. But both of them are found out to be less than when using epoxy separately. Therefore, all percentages proved to be adequate, and the $40 \%$ percentage of glass in the epoxy had higher effect on reduce the thermal conductivity.

According to water absorption, epoxy reinforced with porcelain is lower water absorption than 
epoxy reinforced by glass. Hence all percentages revealed that adding waste materials, glass and porcelain, improved the quality of insolation. The $40 \%$ percentage of porcelain in the epoxy had higher effect on Water Absorptivity Rate (0.0431).

\section{References}

1. Hodgkin, J.H., Simon, G. P., and Valery, R. J , (1998) , "Thermoplastic Toughening of Epoxy Resins: a Critical Review", Polymers for Advanced Technologies, Volume 9, Issue 1, J.Wiley online library.

2. Chakrapa Tuakta, (2005), "Use of Fiber Reinforced Polymer Composites in Bridge Structure", Master of Engineering in Civil and Environmental Engineering at the Massachusetts Institute of Technology, USA

3. Akbar Afghi-Khatibia, and Yiu-Wing Maib, (2002), "Characterisation of fibre/matrix Interfacial degradation under cyclic fatigue loading using dynamic mechanical analysis", Composites: Part A 33, 1585 - 1592 , Elsevier Science Ltd .

4. Hussain M.; Oku Y.; Nakahira A.; and Nihara K, (1996) , "Effects of wet ball-milling on particle dispersion and mechanical properties of particulate epoxy composites", Materials Letters, Volume 26, Number 3 , pp. $177-184(8)$.
5. ASTM C138/C138M, (2010), Standard Test Method for Density (Unit Weight), Yield, and Air Content (Gravimetric) of Concrete.

6. Ultrasonic Testing of Materials at Level 2, Training Manual for Non-Destructive testing Techniques, Austria: IAEA, June, (1988).

7. B.S. 1881: Part 203, "Recommendation for Measurement of Pulse Velocity through Concrete” British Standard Institute 1997.

8. ASTM C1113 (2010) Standard Test Method for Thermal Conductivity of Refractories by Hot Wire (Platinum Resistance Thermometer Technique).

9. ASTM D 570, (2010), Standard Test Method for Water Absorption of Plastics, ASTM International, 100 Barr Harbor Drive, PO Box C700, West Conshohocken, PA 19428-2959, United States.

10. Jyoti L.and V.R. Singh, (2004), "Acoustic behavior of plastics for medical applications" Indian Journal of Pure and Applied Physics, Vol.42, pp $595-599$.

11. Jacob O. et al., (2015)," Development of Roofing Sheet Material Using Groundnut Shell Particles and Epoxy Resin as Composite Material”, American Journal of Engineering Research (AJER), Vol. 4, Issue-6, pp-165173.

\section{تلعيم خواص العزل لبوليمر الأيبوكسي بأستخدام المخلفات

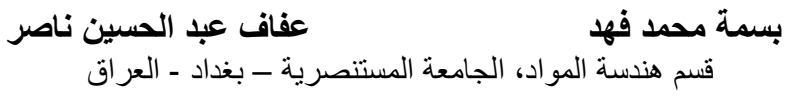 \\ afaf_alshmari@yahoo.com}

الخلاصـــة

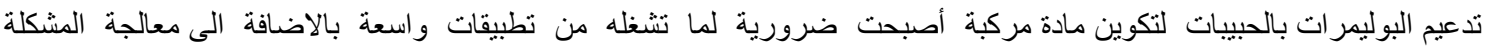

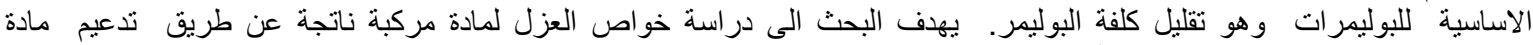

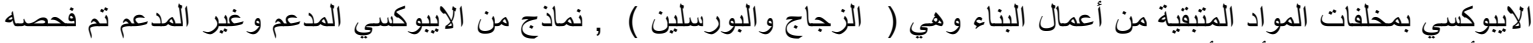

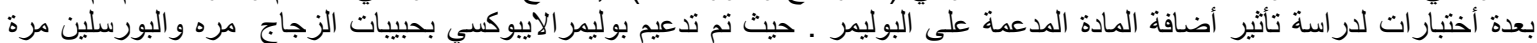

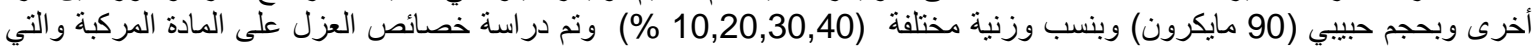

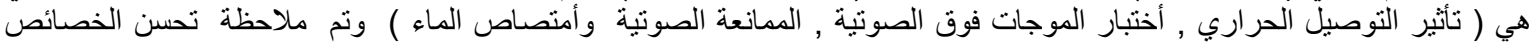

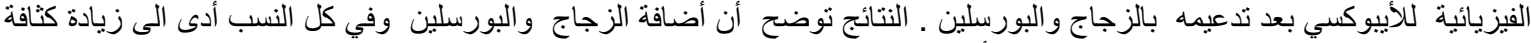

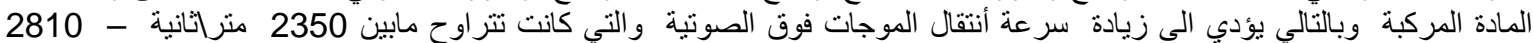

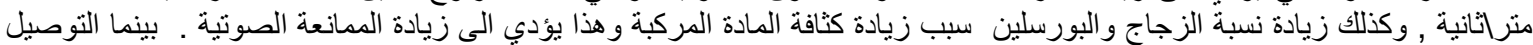

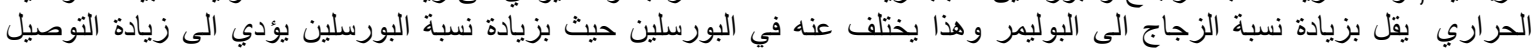

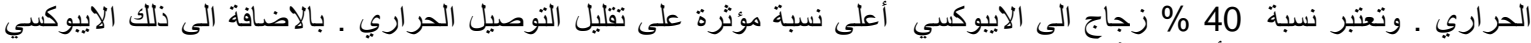

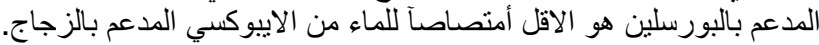

